\title{
A EJA na formação docente: uma experiência na Faculdade de Educação da Universidade Federal de Uberlândia
}

Andressa Garcia Castilho', Adriana Carolina Soares dos Santos ${ }^{1}$, Adriana Cristina Omena dos Santos ${ }^{2}$

\begin{abstract}
Resumo
Este artigo pretende discutir a formação do professor da Educação de Jovens e Adultos (EJA), relacionando-a com a nossa experiência em uma turma da Faculdade de Educação da Universidade Federal de Uberlândia, em Minas Gerais. Para isso, será feita uma breve apresentação histórica dessa modalidade de ensino no Brasil e na América Latina, expondo a sua importância como política pública brasileira e elemento de transformação social. A educação de jovens e adultos é importantíssima, visto que há muitas pessoas que não tiveram a oportunidade de participar da educação regular na idade apropriada. Essas pessoas veem na educação de jovens e adultos, a oportunidade de se inserirem na cultura escrita, assim como um modo de alcançar pleno desenvolvimento pessoal e profissional e, ainda, exercerem o seu papel como cidadãs. O educador da EJA precisa estar em afinidade com este ideal, sendo aliado dos seus alunos neste processo, contribuindo para torná-los cidadãos e sujeitos participativos, críticos e reflexivos.
\end{abstract}

\section{Palavras-chave}

EJA. Formação Docente. Políticas Educacionais.

1. Graduandas do curso de Pedagogia da Faculdade de Educação da Universidade Federal de Uberlândia, membros do Programa de Educação Tutorial (PET) "Conexão de Saberes: Educomunicação". E-mail: andressa_ gcastilho@yahoo.com.br; drika_johvens@hotmail.com.

2. Doutora em Comunicação pela Escola de Comunicação e Artes da Universidade de São Paulo, professora na Faculdade de Educação da Universidade Federal de Uberlândia, tutora do Programa de Educação Tutorial (PET) "Conexão de Saberes: Educomunicação". E-mail: omena@faced.ufu.br. 


\title{
The EJA in theaching: experience at the Faculty of Education of Federal University of Uberlândia
}

Andressa Garcia Castilho*, Adriana Carolina Soares dos Santos*, Adriana Cristina Omena dos Santos**

\begin{abstract}
This article aims to discuss the formation of the Young and Adults Education (EJA), making an association with our experience at a class at the at the Faculty of Education of Federal University of Uberlândia, Minas Gerais. In order to discuss the main subject, a brief historical presentation will be done about this teaching modality in Brasil and all over Latin America, exposing its relevance as a public brazilian policy and as an element of social transformation. The young and adults education is very important considering that many people had no chance to participate in the regular education at the proper age. Those people consider education as the opportunity of inclusion concerning the written culture, as well as achieving full personal and professional development, and still fulfill their role as citizens. The EJA educator needs to agree with this ideal, being allied to the students under this process, contributing to turn the students into a participant, critical and reflexive citizen.
\end{abstract}

\section{Keywords}

EJA. Teacher Training. Educational Polities.

\footnotetext{
* Graduating students of Pedagogy course at the Education Faculty at the Federal University of Uberlândia, Programa de Educação Tutorial (PET) "Conexão de Saberes: Educomunicação" members. E-mail: Andressa_ gcastilho@yahoo.com.br; drika_johvens@hotmail.com.

**Doctor in Communication at the Escola de Comunicação e Artes at the University of São Paulo, professor at the Education Faculty at the Federal University of Uberlândia, Programa de Educação Tutorial (PET) "Conexão de Saberes: Educomunicação tutor "Conexão de Saberes: Educomunicação". E-mail: omena@faced.ufu.br.
} 


\section{Introdução}

\section{Políticas Públicas, Formação Docente e Educação de Jovens e Adultos}

Este artigo pretende discutir sobre a formação do professor da Educação de Jovens e Adultos (EJA), relacionando-a com nossa experiência em uma turma da Faculdade de Educação (FACED) da Universidade Federal de Uberlândia (UFU), em Minas Gerais. Para tanto, será feita uma breve apresentação histórica dessa modalidade de ensino no Brasil e na América Latina, expondo a sua importância como política pública brasileira e elemento de transformação social.

De acordo com Hamze (2012), a EJA nasceu, no cenário da sociedade civil, das "lacunas" do sistema educacional brasileiro. A maior parte das ações governamentais para jovens e adultos foi de políticas assistencialistas, populistas e/ou compensatórias. A educação de adultos é, cada vez mais, o objetivo de políticas públicas específicas. Isto porque é garantida pela Constituição Brasileira de 1988, mas nem sempre ela é concretizada na prática. Portanto, para abordar o tema "Educação de Jovens e Adultos" é imprescindível abordar o conceito de "Políticas Públicas".

Para Dye (apud SOUZA, 2006, p. 1), não existe definição única para o termo "política pública", embora sintetize a definição de política pública como "o que o governo escolhe fazer ou não fazer".

De acordo com Souza (2006), a definição mais conhecida para o termo continua sendo a de Laswell, ou seja, "decisões e análises sobre política pública implicam responder às seguintes questões: quem ganha o quê, por que e que diferença faz" (apud SOUZA, 2006, p. 1). Ainda, segundo Souza (2006, p. 2),

[...] a maior parte das definições enfatizam o papel da política pública na solução de problemas [...] e ignoram a essência da política pública, isto é, o embate em torno de ideias e interesses [...] deixam de lado o seu aspecto conflituoso e os limites que cercam as decisões dos governos [...] deixam também de fora possibilidades de cooperação que podem ocorrer entre os governos e outras instituições e grupos sociais.

As preocupações que desencadearam este trabalho estão diretamente relacionadas às considerações apresentadas acima, haja vista que a Educação de Jovens e Adultos, aqui tratada, é considerada ação das políticas públicas de educação no Brasil.

Neste contexto, vale ressaltar que desenvolver qualquer reflexão acerca do assunto políticas de educação é extremamente delicado, tendo em vista a conjuntura atual da economia política, com seus conglomerados educacionais e as relações econômicas deles decorrentes. Tal situação pode facilmente ser percebida quando nos deparamos com conceitos como "capital informacional", "sociedade do conhecimento" e demais termos específicos da contemporaneidade, estreitamente vinculados à situação atual, na qual a informação e a capacidade criativa e educacional passam a ter papel fundamental na economia de mercado.

Outro ponto que contribui para a problematização do assunto reside no fato de que, paradoxalmente contrário à definição de que política pública seria o que o governo decide ou não realizar, o tema está diretamente relacionado à cidadania. As políticas públicas sejam elas voltadas para a saúde, a segurança ou a educação - são projetos, e todo tipo de formalização jurídico-legal com o objetivo de equacionar os problemas sociais nas diversas esferas e propiciar vida cidadã aos indivíduos de determinada sociedade são ações que visam garantir os direitos fundamentais coletivos e 
difusos da sociedade.

Especificamente acerca da EJA, é de Paiva (apud HAMZE, 2012) as considerações de que foi com a Lei de Diretrizes e Bases da Educação (LDB 9394/96) que o ensino supletivo passou a ser denominado "Educação de Jovens e Adultos". A EJA surgiu a partir da necessidade de oferecer uma educação regular para as pessoas que não puderam ser alfabetizadas na idade apropriada ou que pretendem continuar seus estudos após longo tempo de afastamento da escola. É uma política pública que pretende reparar uma dívida social, criada pelo sistema educacional, que exclui as camadas populares do ensino regular.

Os indivíduos atendidos pela EJA são pessoas que desenvolveram uma rica cultura baseada na oralidade, mas sofrem com as dificuldades de acesso a uma sociedade em que a leitura e a escrita são privilegiadas. Dessa maneira, ficam privados de exercer plenamente a sua condição de cidadãos e, de certa forma, são excluídos da convivência social. Reconhecendo tal necessidade,

A educação passa a ocupar cada vez mais espaço na vida dos indivíduos, não só na das crianças, mas também na dos adultos. [...] Tais associações vão se rompendo à medida que o mercado de trabalho passa a exigir atualização permanente dos conhecimentos, que a expectativa de vida das pessoas e que a terceira idade passa a ter um peso crescente no perfil demográfico e na economia dos países (HADDAD, 2007 apud ARAÚJO, 2011, p. 4).

Assim, pode-se perceber a EJA como um ponto de resistência contra a reprodução de uma sociedade desigual e excludente, sendo muito importante para o desenvolvimento social, cultural e econômico de um país.

No Brasil, a Constituição Federal prevê a educação como direito de todos e dever do Estado e da família, visando, assim, um pleno desenvolvimento pessoal, profissional e a preparação para o exercício da cidadania.
Apesar disso, a educação na idade apropriada, na infância, ainda é privilégio de poucos. A Educação de Jovens e Adultos pretende auxiliar aos que, por diversos motivos sociais, econômicos ou até culturais, não tiveram esta oportunidade na faixa etária adequada. É uma política necessária, visto que a população que não tem acesso a esse tipo de educação ainda é significativa. Pensando na EJA como necessidade social, apresenta-se a seguir um breve relato sobre a história desta modalidade na América Latina e no Brasil. Di Pierro (2008) retrata que a política educacional voltada para jovens e adultos encontrou sujeitos em situações parecidas nos diferentes países da América Latina. No início, essa situação era marcada pela presença de pessoas advindas do meio rural ou indivíduos que sofriam discriminação de gêneros e/ou etnia. Esses alunos ainda trabalhavam sem registro e renda fixa. A autora retrata que, nos últimos anos, os jovens da EJA estudam nessa modalidade para concluírem o ensino e conseguirem melhores posições no mercado de trabalho.

Surgiu, ainda, a presença de mulheres, pois dentre os motivos destacados à busca pelos estudos, estão elencados a necessidade de auxiliarem seus filhos e ultrapassar as objeções feitas à educação feminina. Vale ressaltar que tais dificuldades em permanecer estudando são causadas por uma sociedade patriarcal e uma escola direcionada aos homens, já que nem sempre as mulheres tinham condições de estudar e, quandoera possível, ocurrículoescolar oferecia disciplinas atreladas às tarefas domésticas, como costura, bordado e higienização, preparando a mulher para a vida no lar. A abordagem da EJA como uma educação voltada a sujeitos que, de alguma maneira, foram marginalizados é retratada por Di Pierro (2008, p. 373-374):

No Peru, por exemplo, a escolaridade média dos jovens e adultos varia segundo o local 
de moradia (10 anos de estudos na zona urbana e 6,6 anos na zona rural) e a condição socioeconômica dos indivíduos (10 anos de estudos entre os não pobres, 8,4 anos entre os pobres e 6 anos entre os que se encontram em pobreza extrema). Em El Salvador, a população urbana alcança 6,9 anos de estudos, enquanto na zona rural não supera 3,7 anos de escolaridade. No Brasil, onde o analfabetismo varia de 22,4\%, na região Nordeste, a 6,2\%, na região Sul, e o analfabetismo rural alcança $26,2 \%$ enquanto o urbano é de $8,7 \%$, o pertencimento étnico-racial é importante fator de desigualdade educativa: a taxa de analfabetismo entre os brancos é de 7,1\%, elevando-se a $16 \%$ entre os afrodescendentes. De modo similar, a proporção de indígenas na população dos estados mexicanos se combina a desigualdades socioeconômicas de modo a produzir variações nas taxas de analfabetismo das entidades da Federação de níveis próximos a 20\% em Chiapas, Guerrero e Oaxaca, e taxas em torno de 5\% em Chihuahua e Jalisco. No Equador, a taxa de analfabetismo entre os indígenas é de $28 \%$, enquanto o índice médio nacional é $9 \%$. Na Colômbia, onde a taxa média de analfabetismo é de 7,9\%, essa proporção se eleva a $13 \%$ entre os afro-colombianos e $17,7 \%$ entre os grupos indígenas.

No Brasil, a história da EJA caracterizouse pela falta de oportunidade social, pela ausência de condições e garantias de um ensino para todos. A preocupação com a educação de indivíduos adultos não é algo recente no país. Sua configuração, condições e fins se alteraram desde seu surgimento. Por volta do século XVI, por exemplo, os jesuítas desejavam ensinar a leitura e a escrita para os índios da época, com fins de disseminar a religião católica por meio da educação. Com a Revolução Industrial acontecendo no mundo e afetando países industrializados, apareceu a necessidade de formar trabalhadores que sabiam escrever e ler para executar atividades nas fábricas. Na década de 1930, emergiram propostas educacionais no Brasil que fizeram surgir novas possibilidades para a Educação de Jovens e Adultos, como o advento da Escola Nova, a reformulação da Constituição Nacional e o próprio Plano Nacional de Educação (PNE). Na década de 1940, o governo Vargas trouxe novos debates de democratização no país. A criação do Instituto Nacional de Educação e Pesquisas Anísio Teixeira (INEP) possibilitou o aumento de pesquisas educacionais e a preocupação com a Educação de Adultos.

Concomitantemente a essas iniciativas, organizaçõesinternacionais, comoa Organização das Nações Unidas para a Ciência e a Cultura (UNESCO), estimularam os países a continuarem com a política de alfabetização dos adultos. A Organização das Nações Unidas (ONU), por exemplo, relacionou a importância de educar as gerações com a promoção da Paz Mundial, em plena Segunda Grande Guerra. Nesse período, o objetivo do Brasil era de alfabetizar os alunos adultos em apenas três meses.

Com o final da Segunda Guerra Mundial, porvolta de 1946, observou-se, no Brasil a criação de programas voltados para a alfabetização com o intuito de fazer o indivíduo exercer o direito ao voto, devido à redemocratização do Estado. No ano seguinte, o Ministério da Educação e Cultura (MEC) lançou, em todo país, a Campanha de Educação de Adolescentes e Adultos (CEAA), com a pretensão de alfabetizar os alunos em um período de três meses e fornecer capacitação profissional para a população, pois com o advento da industrialização havia a necessidade de mão de obra qualificada.

Neste período, foram abertas muitas escolas de supletivos no país, sob a coordenação de Lourenço Filho ${ }^{3}$. Entretanto, os resultados não foram satisfatórios, pois, em muitas comunidades rurais, os adultos não tinham condições de acompanhar os cursos. Associado a isso, a baixa remuneração dos profissionais da educação,

3. Lourenço Filho foi um importante educador brasileiro, conhecido, sobretudo, por sua participação no movimento dos pioneiros da Escola Nova e por ter colaborado com o Estado Novo. 
as condições da escola e da sala de aula e a falta de professores capacitados retomavam um ciclo, pois os próprios trabalhadores que não tiveram condições de estudar continuavam sem oportunidade de manter seus estudos. Já o número de Congressos e Conferências Internacionais e Nacionais que discutiam a educação dos adultos crescia a cada ano. Como exemplo, podemos citar a Conferência Internacional de Educação de Adultos e o Seminário Interamericano de Educação de Adultos, em 1949, e o Congresso Nacional de Educação de Adultos, em 1958, considerados avanços em relação à discussão da maneira como essa educação deveria ser destinada aos adultos.

Por volta de 1960, em Pernambuco, destacou-se Paulo Freire, que buscou inserir em sua prática a realidade de seus alunos, o diálogo, a conscientização, o debate político do oprimido e do opressor, a discussão sobre a educação bancária, a exposição das condições em que aconteciam as aulas de alfabetização, o espaço físico destinado, entre outros. O pedagogo destacou-se por suas críticas aos métodos e materiais didáticos da alfabetização de adultos, pelo seu trabalho político, crítico, reflexivo e de constante ressignificação da teoria com a prática, pela sua atuação em regiões carentes e pela defesa de uma educação popular de conscientização: a Pedagogia Crítica.

Para Freire (1996, p. 11):

A leitura do mundo precede a leitura da palavra, daí que a posterior leitura desta não possa prescindir da continuidade da leitura daquele [...]. A concepção do texto a ser alcançada por sua leitura crítica implica a percepção das relações entre texto e contexto.

Portanto, ele acreditava que a leitura não era suficiente quando não havia interpretação e entendimento do texto, relacionando-o com o entendimento de mundo. Dessa maneira, sempre buscava ir além das propostas educacionais da época. Para Freire, se alguns primavam pela alfabetização dos adultos, com fins de promover a educação, o pedagogo deveria estar além, trabalhando com a conscientização das classes dos oprimidos pelo sistema. Paulo Freire tinha o objetivo de conscientizar as camadas populares, não ensinava a palavra ou leitura com a finalidade de ensinar os adultos ou tornálos capazes de redigir texto, estava engajado em discussões políticas de mudanças sociais.

As campanhas internacionais criadas pela UNESCO, em 1960, ajudaram a educação destinada aos jovens e adultos a ganhar impulso no Brasil, pois, de um lado, reconheciam a importância da proposta de Paulo Freire e, de outro, auxiliavam a Igreja junto ao Estado em campanhas de Alfabetização Solidária. No Congresso Nacional de Educação de Adultos, tudo se direcionou com o intuito de criar condições para a melhoria dessa modalidade de ensino, contudo devido ao Golpe Militar, em 1964, tais programas foram extintos.

O Golpe Militar fez repreender os movimentos de classe popular, pois estes representavam perigo para a nova política de governo do país. Três anos mais tarde, o governo assumiu as atividades educacionais, lançando, em 1967, o Movimento Brasileiro de Alfabetização - MOBRAL, que se constituiu em uma centralização do processo de alfabetização. Por meio deste movimento, apenas o Estado poderia escolher e lançar os recursos didáticos, a produção de materiais e coordenar a supervisão e a orientação pedagógica. Um dos reflexos dessa política governamental teve como resultado a ausência de contextualização do ensino em relação à realidade dos alunos ao utilizar nas cartilhas exemplos que não eram comuns a região ou cotidiano dos alunos. Contudo, a proposta tinha como finalidade acabar com o analfabetismo em dez anos.

Percebe-se que, no país, havia duas propostas de Educação de Jovens e Adultos que se diferenciavam em muitos sentidos. Enquanto Freire preocupava-se em abranger 
o contexto do aluno, o MOBRAL desejava apenas instruir a população. Os métodos e objetivos das duas propostas preconizavam uma formação de indivíduos totalmente diferentes, um pensante, o outro reprodutor. Com a repressão da época, no entanto, Freire foi exilado no Chile, e perdemos a sua proposta educacional. Aproximadamente depois de duas décadas de sua criação, o MOBRAL foi extinto, transformando-se na Fundação Educar. Já em 1971, a Lei de Diretrizes e Bases da Educação (LDB 5692/71), representou um avanço para a educação de adultos ao estabelecer a modalidade de Supletivo, cujo objetivo era criar condições para que jovens e adultos que não houvessem concluído o ensino regular, continuassem seus estudos. O Art. 24 da LDB 5692/71 determinava que essa modalidade tivesse como intuito educar aqueles que não tiveram oportunidade e o Art. 25 deliberava que as aulas poderiam ser ministradas por meios de comunicação que permitissem alcançar o maior número de alunos, como o rádio e a televisão. Apesar de serem ferramentas importantes, para a classe social que não tinha acesso aos estudos, isso não representava grandes avanços, pois tais eletrodomésticos tinham um valor comercial não acessível para as classes populares. $\mathrm{Na}$ década de 1980, com o fim da Ditadura, a redemocratização do ensino, e a própria obrigatoriedade do ensino de EJA pela Constituição Federal, houve um aumento do mero de pesquisas sobre a Educação de Jovens e Adultos e suas finalidades.

Nos anos 1990, essa modalidade de ensino ganhou reconhecimento internacional como possibilidade de promoção à cidadania. No Brasil, deixou de ser responsabilidade da União, ficando a cargo dos estados e municípios após a extinção da Fundação Educar pelo presidente Fernando Collor com o objetivo de poupar recursos. Naquele momento, começaram a acontecer diversos encontros para discutir e debateraEJA. Apósa 5ํConferência Internacional de Educação de Adultos (CONFINTEA V), sucederam-se diversos encontros - como o Encontro Nacional de Educação de Jovens e Adultos - ENEJA - e forúns, entre outros.

Nos anos 2000, houve um grande avanço social no país em relação à Política Pública de Formação de Adultos, sendo que, em 2003, sob o governo do então presidente Luiz Inácio Lula da Silva, foi lançado o Programa Brasil Alfabetizado de Formação de Jovens e Adultos, tendo como objetivo a diminuição dos índices de analfabetismo no país. No Brasil Alfabetizado, o Ministério da Educação e Cultura (MEC) seria reponsável pela manutenção do programa juntamente com Estados, Municípios e Universidades. É preciso uma conscientização geral de que a EJA não tem o papel de eliminar o analfabeto, e sim erradicar o analfabetismo. O ensino na EJA ocupa-se não só da alfabetização, como também da formação continuada. Muito além de conseguir decifrar um código linguístico escrito, o aluno deve compreendêlo e utilizá-lo, transformando a leitura e a escrita em instrumentos úteis a sua vida e a sua realidade cotidiana. O papel dessa modalidade de ensino é realmente incentivar o desenvolvimento contínuo dos indivíduos e fazê-los participar da realidade social que se constrói cotidianamente a sua volta.

O intuito da EJA é formar cidadãos críticos, que participem conscientemente do processo de construção da realidade social. Dessa forma, espera-se com essa modalidade de ensino o incentivo ao diálogo e à formação da consciência crítica, tal qual preconizava Paulo Freire.

A proposta de Paulo Freire baseia-se na realidade do educando, levando-se em conta suas experiências, suas opiniões e sua história de vida. Esses dados devem ser organizados pelo educador, a fim de que as informações fornecidas por ele, o conteúdo preparado para as aulas, a metodologia e o material 
utilizados sejam compatíveis e adequados às realidades presentes. Educador e educandos devem caminhar juntos, interagindo durante todo o processo de alfabetização (LOPES; SOUSA, 2005, p. 11).

Para Lopes e Sousa (2005), o objetivo de Paulo Freire e seu método é a libertação, não só cognitiva, mas também sociocultural e política. O homem é um ser político, e por não saber do seu poder de transformação e intervenção da realidade, acaba sujeitandose a ela e as condições por ela impostas. A falta de conhecimento, neste sentido, devese, em grande parte, ao ensino tradicional que coloca o aluno em uma posição de observador e de sujeito não ativo na sua própria realidade, como tábula rasa que só tem a receber, e valoriza os conteúdos fragmentados, isolados e distantes da realidade desse aluno.

De acordo com o Parecer no 11/2000 do Conselho Nacional de Educação e da Câmara de Educação Básica, que regulamenta as diretrizes curriculares nacionais para a educação de jovens e adultos, essa modalidade precisa ocupar-se de fato com a cultura do educando, preparando-o para o mercado de trabalho e qualificando-o para o exercício pleno de sua cidadania. A educação é um instrumento de libertação. Pode não mudar todas as injustiças e nem resolver todos os problemas sociais, mas transforma a vida das pessoas, fazendo com que elas adquiram o poder de reescrever sua própria história.

De acordo com este contexto, é possível perceber como o papel do professor é importante na construção deste processo. O aluno que está na EJA geralmente enfrenta um processo complicado, pois encara problemas como o preconceito, a vergonha, a crítica, o insucesso. Por isso, o professor dessa modalidade tem um papel essencial no sentido de compreender o aluno e sua realidade, acreditar nas suas possibilidades e capacidades, auxiliando-o na etapa de inserção na sociedade letrada e na busca de seu desenvolvimento pessoal e profissional.

De acordo com Lopes e Sousa (2005, p. 2),

é papel do professor, especialmente do professor que atua na EJA, compreender melhor o aluno e sua realidade diária. Enfim, é acreditar nas possibilidades do ser humano, buscando seu crescimento pessoal e profissional.

Diferentemente das crianças menores, os alunos da EJA trazem uma grande bagagem cultural e social, e tem necessidades específicas como a formação profissional e a reinserção social. Então, é fundamental que o educador conheça os alunos com quem vai trabalhar, por meio do cadastro ou do diagnóstico inicial, procurando desenvolver as atividades de ensino de acordo com os conhecimentos e a realidade apresentada pelos estudantes. O intuito é que se construa uma prática participativa e democrática, longe dos princípios liberais do professor como centro e conhecedor de todas as coisas.

A capacitação contínua do professor da EJA faz-se extremamente importante, tornando possível um ensino cada vez mais qualificado. De acordo com Lopes e Sousa (2005, p. 14),

progredir não significa apenas adquirir novos conhecimentos. É abrir a própria consciência para as inovações que surgem diariamente e repensar a própria metodologia de ensino.

O aluno deve sentir-se incorporado às práticas de ensino-aprendizagem, pois tem muito a contribuir para a construção deste processo. A apresentação do professor como um aliado é imprescindível para que o aluno não se sinta inferiorizado e discriminado, e sim responsável e participante do seu próprio processo de aprendizagem. 


\section{A EJA em espaços não escolares: a experiência de graduandas na Faculdade de Educação da UFU}

Ninguém nasce odiando outra pessoa pela cor de sua pele, por sua origem ou ainda por sua religião. Para odiar, as pessoas precisam aprender. E se podem aprender a odiar, podem ser ensinadas a amar.

Nelson Mandela

O projeto "A EJA em espaços não escolares", já existia na Faculdade de Educação da Universidade Federal de Uberlândia desde 2006 e, em 2011, passou a ser vinculado ao PET Conexões Educomunicação.

Os alunos do projeto são pacientes em tratamento do Centro de Atendimento Psicossocial (CAPS) de Uberlândia. A proposta do CAPS é atender, de forma humanitária, pessoas com baixa renda que sofrem de problemas psicológicos e psicossociais, procurando reinserir essas pessoas na sociedade. Os problemas psicossociais são os causados por dificuldades na relação indivíduo-meio, como por exemplo, a esquizofrenia, a depressão e o Transtorno Obsessivo Compulsivo (TOC).

O CAPS, juntamente com parceiros, oferece várias oficinas das quais os pacientes participam de acordo com a afinidade com cada atividade. Dessa forma, eles têm a oportunidade de elevar a sua autoestima e se reinserir no convívio social, modificando o seu olhar para a sociedade e vice-versa.

O PET Conexões Educomunicação, ligado a este projeto, surge de uma junção do Programa de Educação Tutorial (PET) com o Programa Conexões de Saberes (PCS), pelo Ministério da Educação, em 2010. O objetivo dos grupos PET Conexões é democratizar o acesso à universidade e proporcionar a permanência com qualidade de alunos oriundos das camadas populares da sociedade. Para isso, o programa baseia-se nos três pilares: ensino, pesquisa e extensão.

O PET Conexões Educomunicação é interdisciplinar e abarca alunos dos cursos de Pedagogia, Comunicação Social com habilitação em Jornalismo e demais licenciaturas. O PET Conexões tem a preocupação com a formação crítica, reflexiva e política do indivíduo que entra na universidade. Observa-se, portanto, o desafio em estender essa formação para além dos muros da universidade, por meio dos projetos de extensão. A EJA em espaços não escolares é uma oportunidade de colocar em prática os objetivos colocados pelo PET Conexões Educomunicação e atender a essa necessidade de formação de alunos universitários.

Depois de contextualizado o projeto, destaca-se os desafios encontrados em nossas práticas, como estudantes universitárias, na tentativa de inserir esses pacientes em um contexto rico de letramento, para que eles possam se sentir parte da sociedade, reorganizando a sua condição como cidadãos. Discutem-se, também, algumas de nossas experiências enquanto pesquisadoras/monitoras e relata-se o desafio de conciliar a teoria e colocar em prática o aprendizado do nosso curso.

O projeto configura-se em um espaço de múltiplas aprendizagens, tanto por parte de educadores quanto dos educandos e, atualmente, conta com a colaboração de alunas do terceiro e quarto anos do Curso de Pedagogia da Universidade Federal de Uberlândia. Alternadamente, as monitoras auxiliam no planejamento, ministram aulas e conduzem as atividades em sala, sendo que todas participam do processo como um todo.

Vale ressaltar que todas as monitoras do projeto estão em período de formação. Por isso, a troca de conhecimentos e saberes entre a equipe constitui-se em um instrumento importante para o planejamento e a preparação das aulas. Pensando nisso, o grupo é dividido em dois subgrupos por ano cursado, para que a responsabilidade de executar a aula esteja sempre a cargo de uma equipe diferente. Quanto ao planejamento, ele é realizado 
em conjunto com o grupo, sempre partindo de uma temática central. Essa abordagem é trabalhada de forma interdisciplinar, pois, além de cada membro do grupo ter uma afinidade com determinada área do saber, o direcionamento de um único conteúdo poderia empobrecer nossas práticas e a aprendizagem dos alunos.

No projeto, a ideia central é trabalhar com as múltiplas linguagens, partindo de algo que faça parte da realidade dos discentes, conforme dizia Paulo Freire (1984, p. 40):

A saída para a condição opressora está no processo educativo problematizador que possibilita ao homem refletir sobre sua realidade oprimida e buscar através do diálogo constante com seus pares superar a contradição que desarmoniza; e a superação envolve o homem que está no mundo e com o mundo, participando ativamente no processo de construção social.

Com os temas, o grupo procura enriquecer o trabalho, a fim de conduzir os alunos a terem uma postura mais crítica da realidade vivenciada. Nosso desafio, além de tentar sempre problematizar a aula, encontra-se na pluralidade de formação do grupo, pois todas as monitoras são responsáveis por executarem uma aula, o que poderia atrapalhar uma sequência didática das aulas e a aprendizagem dos alunos. Com isso, decidiu-se explorar e manter um tema central, a fim de evitar a mudança de conteúdo a toda aula, construindo uma linha de raciocínio.

Atualmente, o projeto atende em torno de vinte alunos. Durante o trabalho, foi possível perceber que muitos desses alunos tinham interesses diferentes quanto à aprendizagem de conteúdos, algo natural para uma turma de jovens e adultos. Devido a essa diversidade e da vontade do grupo em colaborar com os alunos, foi estabelecido um planejamento que tivesse uma divisão, um horário destinado ao estudo de um tema central e, no segundo momento, o para casa.
O caderno de para casa é um elemento que contribui muito para o trabalho. Foram distribuídos alguns cadernos por meio do projeto, nos quais são direcionadas atividades para serem feitas fora da sala de aula. Diferente de um caderno de para casa utilizado na escola, o objetivo dele, no projeto, é explorar o interesse do aluno, ou seja, focar naquilo que ele gostaria de aprender. Também contribuiu na medida em que os alunos não têm condições financeiras de comprar materiais para estudar em casa e o tempo deles na universidade é pouco, pois as aulas são semanais com a duração de duas horas e meia.

Por meio desses cadernos, é possível atingir os objetivos de cada aluno, as suas peculiaridades em relação ao conteúdo e a profundidade que cada um precisava. Vale ressaltar que esses alunos são jovens e adultos e não poderiam se dedicar exclusivamente aos estudos, por isso não foi exigido que eles fizessem tarefas de casa. Essas tarefas são sugeridas para auxiliar nas dificuldades no dia da aula.

$\mathrm{O}$ resultado surpreendeu todo $\mathrm{O}$ grupo de monitores. A atividade teve um alcance maior que o esperado entre os alunos, ajudou a suprir grande parte das necessidades individuais e motivou os alunos que passaram a participar mais efetivamente das aulas, além de aumentar a frequência.

\section{Considerações Finais}

Este artigo procurou situar o leitor sobre o percurso da EJA na América Latina e no Brasil, além de apresentar a experiência de graduandas em atividades extensionistas de EJA na UFU. Participar da educação de jovens e adultos, na universidade, permitiu a construção de um olhar diferenciado sobre esse público e a modalidade de educação para ele voltada, conhecendo a história, a necessidade da existência da EJA como política pública educacional, nos aproximando das teorias de Paulo Freire e acrescentando muito 
mais valor às teorias aprendidas na graduação. A relação que esta experiência proporcionou da teoria e da prática permitiu construir e compreender o sentido da práxis, tão comentada nas teorias educacionais. Nesse sentido, cabe ressaltar a importância da Educação de Jovens e Adultos, pela sua história, pelos indivíduos atendidos por ela. Sentimo-nos privilegiadas em poder participar deste projeto durante nossa formação acadêmica.

\section{Referências}

ARAÚJO, M. S. de O. Educação de jovens e adultos: gestão democrática e ação participativa dialógica em movimento. 2011. Disponível em: <http://www.anpae.org.br/simposio2011/ cdrom2011/PDFs/trabalhosCompletos/comunicacoesRelatos/0324.pdf>. Acesso em: 22 mar. 2012.

DI PIERRO, C. M. Educação de Jovens e Adultos na América Latina e Caribe: trajetória recente. Cadernos de Pesquisa, v. 38, n. 134, p. 367-391, maio-ago. 2008.

FREIRE, P. Pedagogia do Oprimido. Rio de Janeiro: Paz e Terra, 1984. 1996.

. A importância do ato de ler: em três artigos que se completam. 49. ed. São Paulo: Cortez,

HAMZE, A. A educação de jovens e adultos no cenário das políticas públicas. 2012. Disponível em: $\quad<$ http://educador.brasilescola.com/politica-educacional/a-educacao-de-jovens-e-adultos. htm>. Acesso em: 15 mar. 2012.

LOPES, S. P.; SOUSA, L. S. EJA: uma educação possível ou mera utopia? Revista de Educação de Jovens e Adultos, v. 2, n. 3, p. 1-100, dez. 2003.

SOUZA, C. Políticas públicas: uma revisão da literatura. Sociologias, Porto Alegre, v. 8, n. 16, jul.dez. 2006.

Submetido em 2 de agosto de 2012.

Aprovado em 10 de dezembro de 2012. 